\title{
Battery Charge and Discharge Strategies in Terms of Entropy Production ${ }^{+}$
}

\author{
Martí Garcia-Corominas and Angel Cuadras \\ Universitat Politècnica de Catalunya, BarcelonaTech, EEBE-DEEL, Terrassa, Spain \\ + Presented at the Entropy 2021: The Scientific Tool of the 21st Century, 5-7 May 2021; Available online: \\ https://sciforum.net/conference/Entropy2021/.
}

Published: 5 May 2021

At present, batteries are the bottle neck of electric mobility, both for their cost and management. In this contribution, we aim to evaluate optimal battery charge in terms of entropy production and relate it to charging time and cost, with the aim to take advantage of vehicle-to-grid configuration. Liion batteries are usually charged using a constant current constant voltage strategy (CC-CV). The shift between $\mathrm{CC}$ and $\mathrm{CV}$ occurs when the battery reaches the maximum charging voltage. In terms of energy efficiency, this is not the most efficient approach. We develop Matlab ${ }^{\circledast}$ software scripts to simulate the performance of a real cell during charging by shifting from constant current to constant voltage at different battery state of charge $b$. We carried out a variational analysis of the charging/discharging processes in order to obtain its entropy performance so that it could be related to optimal energy efficiency in terms of $b$ and in terms of cost/benefit according to the present Spanish electric market prices. Finally, these magnitudes studied at different charge rates and at different battery aging levels. We find that entropy is a valuable magnitude to characterize battery charge/discharge processes and find the optimal strategy in terms of cost, time and energy.

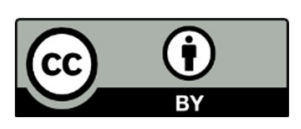

(C) 2021 by the authors. Licensee MDPI, Basel, Switzerland. This article is an open access article distributed under the terms and conditions of the Creative Commons Attribution (CC BY) license (http://creativecommons.org/licenses/by/4.0/). 